Weaning from mechanical ventilation

\section{Streamlining weaning: protocols and weaning units}

\section{A K Simonds}

\section{Use of weaning protocols and specialised weaning units for patients who fail to wean from mechanical ventilation}

D scontinuation of ventilation is estimated to take up to $40 \%$ of the total duration of ventilatory support, and around 3-6\% of patients admitted to the intensive care unit (ICU) require a prolonged course of mechanical ventilation (MV). ${ }^{1}$ Patients being liberated from ventilatory support therefore occupy a significant number of ICU beds and have a major impact on healthcare resources. There have been several recent key developments in the field of weaning-the use of weaning protocols, ventilatory strategies to reduce the need for invasive ventilation and facilitate successful extubation, and the creation of regional long term ventilator units. All have the potential to affect weaning outcome, but how valuable are they in practice?

\section{WEANING PROTOCOLS}

In 1996 Ely and colleagues ${ }^{2}$ showed that the implementation of a standardised protocol of daily trials of spontaneous breathing performed by nursing staff reduced the total duration of MV from 6 to 4.5 days, and complications such as need for reintubation, tracheostomy, and duration of $M V>21$ days were also decreased, resulting in a reduction in ICU costs. Similar protocols have reduced the duration of MV, although not necessarily ICU stay. ${ }^{3}$ Smyrnios et al implemented a hospital-wide weaning protocol and found a decrease in the need for tracheostomy by a third and a reduction in mean hospital stay from 37.5 to 24.7 days, resulting in a $30 \%$ fall in cost per case.

Despite these findings, weaning protocols have not been taken up universally. For example, in a survey of ICUs in England commissioned by the Department of Health, protocol directed weaning was reported in less than one in five units. ${ }^{5}$ This may be due to a variety of reasons including differences in healthcare practice and cultures, and the fact that the findings may not be universally applicable. Randolph et $a l^{6}$ compared a weaning protocol with standard care (no defined protocol) in infants and children with acute illnesses requiring $\mathrm{MV}$ and found that, in contrast to adult patients, the majority of children were weaned within 2 days and the weaning protocol did not influence the duration of MV. Furthermore, a recent controlled trial $^{7}$ of adults requiring $\mathrm{MV}$ for $>24$ hours showed no difference in duration of MV, ICU stay, need for re-institution of MV, or hospital mortality in the group treated with a nursing/respiratory therapist driven protocol compared with those in whom weaning was managed off protocol by the supervising physician.

Does this latest study mean that weaning protocols are unnecessary and unhelpful? Almost certainly not. Standard practice evolves by physicians incorporating examples of best practice and research findings into their day to day care-as Tobin has noted, ${ }^{8}$ the issue is not what is wrong with protocol directed care but what is right with standard management. It is also important to note that this study ${ }^{7}$ with a negative outcome was carried out in a closed intensivist run ICU with high levels of staffing, and a routine management template was used to encourage staff to address weaning issues each day. So a fairly comprehensive "protocol" was in place anyway. It follows that protocols and guidelines may drive up the standard of routine care, especially in open ICUs, and should be evaluated and adapted to the site they are operating in to improve and update current management pathways.

\section{NEW VENTILATORY AND EXTUBATION STRATEGIES}

There is now a substantial body of evidence confirming that the application of non-invasive ventilation (NIV) in acute excerbations of COPD can prevent the need for intubation, such that NIV should be available on a 24 hour basis in units managing patients with acute respiratory failure. ${ }^{9-12}$ For intubated patients who have failed a spontaneous breathing trial for 30 minutes to 2 hours, there is little point in repeating the trial before 24 hours has elapsed. During this period patients should receive optimum ventilatory support in assist mode to allow some muscle activity and patient control over the ventilation delivered. ${ }^{1}$ Brochard et $a l^{13}$ have shown that gradually reducing pressure support ventilation is superior to intermittent mandatory ventilation or progressive spontaneous breathing trials in reducing weaning time. Early extubation onto NIV has been shown to be effective in patients with COPD. Nava et $a l^{14}$ found that non-invasive pressure support ventilation reduced weaning time, shortened ICU stay, decreased the incidence of nosocomial pneumonia, and improved 60 day survival in COPD patients extubated on to NIV 48 hours after admission with a severe hypercapnic exacerbation compared with continued standard invasive ventilation. In addition, in a heterogeneous group of patients with persistent weaning failure randomised to either NIV or continued invasive ventilation, the NIV group had a shorter total period of ventilation, reduced ICU stay (14.1 $v 25$ days), and reduced hospital stay (27.8 $v 40.8$ days) $(p=0.026) .{ }^{15}$ The need for a tracheostomy was markedly reduced $(1.5 \% \mathrm{v}$ $13.5 \%$ ) and the conventional (invasive) weaning approach proved to be an independent risk factor for decreased ICU and 90 day survival (odds ratio 6.6, $\mathrm{p}=0.035)$. Indeed, the results were so clear cut the trial was halted after planned interim analysis. ${ }^{15}$ These findings suggest that NIV should be considered early in the process of weaning, before a tracheostomy is performed unless there are specific indications for this (such as upper airway obstruction, severe bulbar weakness). By the same token, NIV has increasingly been used in patients who develop post extubation respiratory failure. Here one should apply a note of caution-while a historical case control study in patients with COPD showed that use of NIV reduced the need for reintubation from $67 \%$ to $20 \%{ }^{16}$ two recent prospective randomised trials ${ }^{17}{ }^{18}$ have shown no advantage to the use of NIV in post extubation respiratory failure. In fact, Esteban et al ${ }^{18}$ showed an increase in mortality in patients treated with NIV compared with those receiving standard management. There are several possible explanations for this discrepancy. Firstly, in the trial by Esteban et al ${ }^{18}$ only $10 \%$ of patients had COPD while the remainder had a variety of conditions including pneumonia, postoperative respiratory failure, trauma, cardiac failure, and ARDS. Most work suggests that NIV is more effective in patients with COPD than in those with acute hypoxaemic normocapnic respiratory failure. Secondly, the median time from extubation until reintubation was longer in the NIV group ( $12 \vee 2.5$ hours), suggesting that use of NIV may delay reintubation, thereby affecting outcome adversely. 
Furthermore, spontaneous breathing trials provide an overall guide to ventilatory capacity but signify little regarding cough efficacy and the ability to clear bronchial secretions if an endotracheal tube or tracheostomy is in situ. Salam et $a l^{19}$ evaluated the extent to which cough efficiency (measured by cough peak flow), neurological function, and the volume of endotracheal secretions affects the outcome of extubation in patients who had passed a spontaneous breathing trial. A cough peak flow of less than $60 \mathrm{l} / \mathrm{min}$ increased the likelihood of extubation failure nearly fivefold, and the combination of low cough peak flow, volume of secretions $>2.5 \mathrm{ml} /$ hour, and failure to respond to simple commands produced an extubation failure rate of $100 \%$ compared with only $3 \%$ in those without these risk factors. This study ${ }^{19}$ was performed in 88 routine ICU admissions with diagnoses including pneumonia, COPD, congestive heart failure, asthma and sepsis, and there was no particular emphasis on neurological or neuromuscular patients. Cough efficacy, neurological status, and the ability to clear secretions are likely to assume even greater importance in patients with neuromuscular weakness, and the results suggest these assessments (including evaluation of bulbar and swallowing function) should be added to spontaneous breathing trials in neuromuscular and neurological groups. Additional strategies such as a combination of NIV and cough insufflator/exsufflator devices ${ }^{20}{ }^{21}$ may be valuable in these patients and reduce the need for tracheostomy ventilation. ${ }^{22}$ Clearly, in neuromuscular patients with a history of gradual decline before acute ventilatory decompensation, or a progressive condition such as amyotrophic lateral sclerosis/motor neurone disease, failed trials of spontaneous breathing should not be fruitlessly and demoralisingly repeated but should prompt early referral for consideration of long term ventilatory support.

\section{WEANING/LONG TERM VENTILATOR UNITS}

Having applied strategies to optimise the probability of weaning success, what can be done for patients who fail to wean simply or who are likely to need long term ventilatory support, and how many individuals fall into this category? Various definitions have been used, but weaning delay can be considered to be the need for ventilatory support for more than 2 weeks in the absence of any nonrespiratory factor preventing weaning, and the term weaning failure is used if this persists for 3 weeks or more. In the USA it has been estimated that there are over 11000 ventilator dependent patients in acute care facilities, costing over \$9 million a day. ${ }^{23}$ A 1 year survey ${ }^{24}$ in the Northern region of England identified 161 patients with weaning delay; these patients comprised $2.5 \%$ of ICU admissions and occupied $6 \%$ of ICU beds in the region. A subsequent NHS Modernisation Agency point prevalence survey of critical care facilities in England published in 2002 showed that approximately $8 \%$ of ICU patients had weaning delay and $7 \%$ weaning failure. ${ }^{5}$ The most common reasons for weaning failure were chronic lung disease, cardiac impairment, neurological disease, or neuromuscular disease. As a result of these findings, the NHS Modernisation Agency has recommended the creation of a specialist NIV service integrated into the critical care network and the provision of a UK-wide service for long term invasive and non-invasive respiratory support for patients who have failed to wean. ${ }^{5}$ The activity of one such unit is described comprehensively in this issue of Thorax by Pilcher et $a^{25}$ who present the outcome from a specialised weaning programme over 4 years. Of approximately 150 weaning delay patients who had received MV for around 20 days before transfer to the unit, 38\% were weaned completely from ventilatory support, 35\% required home ventilation, and $27 \%$ died before leaving hospital. Survival was best in patients with neuromuscular disease (who, conversely, were most likely to remain ventilator dependent) and worst in postoperative patients. Length of ICU stay before transfer, age, and APACHE II score on admission were key predictors of outcome. Female sex was associated with an increased probability of weaning, but this finding may be partly a consequence of the high likelihood of Duchenne patients (male) requiring home ventilation. The economic analysis is helpful, but further detailed work is required in this area.

In an earlier study, Smith and colleagues $^{26}$ found a survival rate of $90 \%$ compared with a predicted survival from APACHE II score of 53\% in 40 consecutive admissions to a regional weaning unit. Nearly $30 \%$ of these patients required home ventilation-but only three via tracheostomy. To set this within a European perspective, outcome data $^{27}$ from a German regional unit accepting patients with weaning delay showed $60 \%$ of referrals had COPD, mortality was $24 \%$, and $31 \%$ were discharged using NIV. Here, too, the survival rate was related to the underlying diagnosis-patients with thoracic cage and neuromuscular disorders faring better than those with COPD.

In the USA there is a longer tradition of post ICU care delivered in long term facilities, and this has been substantially finance driven. A growing number of case series reports of patients with weaning failure has shown a common pattern-average age on admission of around 70 years, predominant diagnoses of COPD or postoperative cases, with approximately $60 \%$ surviving to discharge from the facility, $30 \%$ surviving at 1 year, and around half weaned completely from ventilatory support. ${ }^{28-31}$ A multicentre study of 23 units commissioned by the US National Association of Long Term Hospitals has recently been set up to identify characteristics of the population at risk, treatment outcome, and estimate costs of care.

The advantages and disadvantages of weaning/long term ventilator units should be considered. Results from the European and US case series would suggest that patients whose primary problem is ventilatory dependence can be managed in a less intensive step down unit, thereby reducing costs and facilitating a focus on ventilatory care and rehabilitation. ICU facilities are freed up for patients requiring more complex care such as those with multisystem failure. Survival improves and favourable 1 and 3 year results can be obtained in some subgroups, particularly patients with neuromuscular disease, although outcome remains relatively poor in the elderly and those with COPD, and families have to travel longer distances to visit patients. These centres tend to have greater familiarity with NIV techniques and are able to provide families and carers with competency training in tracheostomy and ventilatory care, and to develop comprehensive home care packages to speed discharge. However, the outcome from weaning units critically depends on the selection criteria used for admission and can be biased if high risk admissions are refused. In many reports acceptance criteria are not made explicit. In addition, results may be influenced by the fact that, as in the study by Pilcher et al, long term units are likely to accept patients from their own or local ICUs more swiftly, thereby improving outcome.

Assuming, however, that targeting resources in this manner is rational, how many long term ventilatory places are required? The Northern region of England survey ${ }^{24}$ included 112 ICU (level 3 ) beds and suggested that a seven-bed weaning unit would be able to cater for $93 \%$ of patients with weaning delay, while a five-bedded unit would cope with $75 \%$ of cases of weaning delay-that is, a ratio of around one bed per 20 ICU beds. When planning the allocation of beds it should be recognised that in some countries many weaning failure patients are colonised or infected with methicillin resistant Staphylococcus aureus (MRSA) as a result of prolonged hospital stay and so 
will require single cubicle areas. These units are often most usefully placed alongside or combined with high dependency/respiratory intermediate care facilities, $^{32}{ }^{33}$ allowing flexible bed use, and can act as a focus for training in NIV and long term ventilation-not least as subspecialty training in ventilatory support is being considered as part of standard respiratory medicine/pneumology training programmes in Europe.

Thorax 2005;60:175-177.

doi: 10.1136/thx.2004.028688

Correspondence to: $\operatorname{Dr}$ A K Simonds, Consultant in Respiratory Medicine, Clinical and Academic Department of Sleep and Breathing, Royal Brompton and Harefield NHS Trust, Sydney Street, London SW3 6NP UK; a.simonds@rbh.nthames.nhs.uk

Declaration of interest: AKS is in receipt of research awards from ResMed Ltd and Breas Medical who manufacture ventilators.

\section{REFERENCES}

1 Maclntyre NR. Evidence-based guidelines for weaning and discontinuing ventilatory support. Chest 2001:120:375-96S

2 Ely EW, Albert AM, Dunagan DP, et al. Effect on the duration of mechanical ventilation of identifying patients capable of breathing spontaneously. N Engl J Med 1996;335:1864-9.

3 Grap MJ, Strickland D, Tormey L, et al. Collaborative practice: development implementation, and evaluation of a weaning protocol for patients receiving mechanical ventilation. Am J Crit Care 2003;12:454-60.

4 Smyrnios N, Connolly A, Wilson MM, et al. Effects of a multifaceted, multidisciplinary, hospital-wide quality improvement program on weaning from mechanical ventilation. Crit Care Med 2002;30: 1224-30.

5 NHS Modernisation Agency Report. Critical care programme. Weaning and long term ventilation. London: NHS Modernisation Agency, 2002.

6 Randolph AG, Wypii D, Venkataraman ST, et al. Effect of mechanical ventilator weaning protocols on respiratory outcomes in infants and children: a randomized controlled trial. JAMA 2002;288:2561-8

7 Krishnan JA, Moore D, Robeson C, et al. A prospective, controlled trial of protocol-based strategy to discontinue mechanical ventilation Am J Respir Crit Care Med 2004; 169:673-8.

8 Tobin MJ. Of principles and protocols and weaning. Am J Respir Crit Care Med 2004;169:661-2.

9 Brochard L, Mancebo J, Wysocki M, et al. Noninvasive ventilation for acute exacerbations of chronic pulmonary disease. N Engl J Med 1995; 333:817-22.

10 Plant PK, Owen JL, Elliott MW. Early use of noninvasive ventilation for acute exacerbations of chronic obstructive pulmonary disease on general respiratory wards: a multicentre randomised controlled trial. Lancet 2000;355:1931-5.

11 Brochard L. Non-invasive ventilation for acute exacerbations of COPD: a new standard of care. Thorax 2000:55:817-8.

12 British Thoracic Society Standards of Care Committee. Non-invasive ventilation in acute respiratory failure. Thorax 2002;57:192-211.

13 Brochard L, Rauss A, Benito S, et al. Comparison of three methods of gradual withdrawal from ventilatory support during weaning from mechanical ventilation. Am J Respir Crit Care Med 1994:150:896-903.

14 Nava S, Ambrosino N, Clini E, et al. Noninvasive mechanical ventilation in the weaning of patients with respiratory failure due to chronic obstructive pulmonary disease. A randomized controlled trial. Ann Intern Med 1998; 128:721-8

15 Ferrer M, Esquinas A, Arancibia $F$, et al Noninvasive ventilation during persistent weaning failure: a randomised controlled trial. Am J Respir Crit Care Med 2003; 168:70-6.

16 Hilbert G, Gruson D, Portel L, et al. Noninvasive pressure support ventilation in COPD patients with postextubation hypercapnic respiratory insufficiency. Eur Respir J 1998;11:1349-53.

17 Keenan SP, Powers C, McCormack DG, et al. Noninvasive positive-pressure ventilation for post extubation respiratory distress: a randomised controlled trial. JAMA 2002;287:3238-44.

18 Esteban A, Frutos-Vivar F, Ferguson ND, et al. Noninvasive positive-pressure ventilation for respiratory failure after extubation. $N$ Engl J Med 2004;350:2452-60.

19 Salam A, Tilluckdharry L, Amoateng-Adjepong Y, et al. Neurologic status, cough, secretions and extubation outcomes. Intensive Care Med 2004;30:1334-9.
20 Bach JR. Mechanical insufflation-exsufflation. Comparison of peak expiratory flows with manually assisted and unassisted coughing techniques. Chest 1993:104:1553-62.

21 Chatwin M, Ross E, Hart N, et al. Cough augmentation with mechanical insufflation/ exsufflation in patients with neuromuscular weakness. Eur Respir J 2003;21:502-8.

22 Bach JR, Ishikawa Y, Kim H. Prevention of pulmonary morbidity for patients with Duchenne muscular dystrophy. Chest 1998; 112:1024-8.

23 Make BJ. Indications for home ventilation in critical care unit patients. In: Robert D, Make BJ Leger $P$, et al, eds. Home mechanical ventilation. Paris: Arnette Blacwell, 1995:229-40.

24 Robson V, Poynter J, Lawler PG, et al. The need for a regional weaning centre, a one-year survey of intensive care weaning delay in the Northern region of England. Anaesthesia 2003;58:161-70.

25 Pilcher DV, Bailey MJ, Treacher DF, et al. Outcomes, cost and long term survival of patients referred to a regional weaning centre. Thorax 2005:60:187-92

26 Smith IE, Shneerson JM. A progressive care programme for prolonged ventilatory failure: analysis and outcome. $\mathrm{Br} J$ Anaesth 1995:75:399-404.

27 Schonhofer B, Euteneuer S, Nava S, et al. Survival of mechanically ventilated patients admitted to a specialised weaning centre. Intensive Care Med 2002;28:908-16.

28 Scheinhorn DJ, Chao DC, StearnHassenpflug MS, et al. Post-ICU weaning from mechanical ventilation: the role of long-term facilities. Chest 2001;120(6 Suppl):482-4S.

29 Scheinhorn DJ, Chao DC, StearnHassenpflug MS. Liberation from prolonged mechanical ventilation. Crit Care Clinics 2002; 18:569-95.

30 Stoller JK, Xu M, Mascha E, et al. Long-term outcomes for patients discharged from a long term hospital-based weaning unit. Chest 2003;124:1892-9.

31 Dasgupta A, Rice R, Mascha E, et al. Four year experience with a unit for long term ventilation (Respiratory Special Care Unit) at the Cleveland Clinic Foundation. Chest 1999; 1 16:447-55.

32 Elliott MW, Baudouin SV. Respiratory intensive care in Europe: lessons for the UK. Thorax 1998; 53:725-6

33 Corrado A, Roussos C, Ambrosino N, et al. Respiratory intermediate care units: a European survey. Eur Respir $J$ 2002;20:1343-50.

fears about medication and side effects, lack of opportunity for patient involvement in treatment decisions, lack of recognition of the coexistence of lay and popular remedies. We stand accused of an enthusiasm for authoritarian, positivist, illness centred medicine. ${ }^{5-10}$ Ethicists show how clinicians can undermine trust by failing to discuss how rationing affects their prescribing or referral decisions; ${ }^{11}$ any patient who says their doctor "prescribes the cheapest of the cheap medicines" ${ }^{12}$ is unlikely to value advice. Educationalists and psychologists argue that teaching knowledge about asthma is inadequate and that the key skills needed are goal setting, problem solving, and development of confidence-a view backed by empirical research in the USA. ${ }^{13-15}$

These perspectives can be grouped together under the general heading of a failure to involve patients sufficiently in their care. Patient centred care is not

high expectations of patients' abilities to self-care are fuelled by trials in selected populations ${ }^{1}$ and politicians with visions of reduced healthcare costs. ${ }^{23}$ The realities of asthma self-management consultation remains the most important opportunity for helping patients to develop the ability to manage their asthma. Rightly, the consultation continues to be deficiencies that hinder success in promoting self-care: the infrequency with which doctors seek and patients air 
about destructive consumerisation and deprofessionalisation, ${ }^{516}$ but acknowledgment of the complementary expertise and knowledge that patients and professionals bring to the consultation. ${ }^{17}$ It incorporates the notion of promoting shared decision making in consultations. ${ }^{18}{ }^{19}$ It is an explicit goal of healthcare reform. ${ }^{2}$ From an ethical standpoint, there is no doubt that patients should exercise autonomy and control over their care. However, while reviews of interventions suggest the goals of increased patient involvement, satisfaction and adherence are often met, improved health and reduced costs have been more elusive. ${ }^{20}$ Providing convincing evidence of these benefits remains a most important challenge.

In this issue of Thorax Caress and colleagues bring a useful contribution to this debate. ${ }^{21}$ In a study of asthmatic subjects drawn from primary and secondary care they show that most want to be more involved in decisions about their asthma care. They show that few people live at the extremes of wanting to make decisions without advice or having them made for them. The study is strengthened by combining qualitative data from interviews with patients to illuminate their positions on decision making.

Very similar findings were reported in hypertensive patients in the USA by Strull and colleagues 20 years ago, which suggests that this is a persistent and generalisable finding. ${ }^{22}$ Using a similar questionnaire design, patients reported higher preferences for involvement than they experienced across five categories. A comparison suggests a trend away from paternalism with fewer patients preferring a fully passive role in 2004 compared with $1984(14 \% \vee 47 \%)$. It is difficult to predict individual preferences, but previous work shows that the desire for involvement broadly relates to condition, context, and demographic factors. For instance, patients wish for greater involvement in decisions for benign versus malignant breast disease, for routine versus emergency care, ${ }^{23}$ and for emotional compared with physical problems. ${ }^{19}{ }^{23-25}$ In general, younger, more educated people prefer greater involvement.

So what remains concerning patient involvement and respiratory care? Research priorities are to find ways to enhance involvement of patients in consultations (particularly where care is increasingly driven by data collection and contract targets), and then to evaluate these in trials, testing their effects on health status and health care use. Promising work in this area needs to be tested in settings outside the USA. ${ }^{13}{ }^{15}$ People with asthma from minority ethnic groups have poorer outcomes for asthma and are rarely involved in treatment decisions, even when language barriers are absent. ${ }^{26}$ Interventions may be of particular benefit in such groups. Layled education programmes for people with chronic disease are becoming integral to modern health care, but with little evaluation. ${ }^{3}$ We need to find out how effective these are in promoting more effective consultations and better health, and whether integration with more traditional professionally led education creates benefits or new problems.

Patients were asking for more involvement in 1984 and continue to do so 20 years later. Our response might improve the health of people with asthma.

The sociologist Talcott Parsons wrote in 1951:

"By the same institutional definition the sick person is not, of course, competent to help himself, or what he can do is, except for trivial illness, not adequate. But in our culture there is a special definition of the kind of help he needs, namely, professional, technically competent help. The nature of this help imposes a further disability or handicap upon him. He is not only generally not in a position to do what needs to be done, but does not 'know' what needs to be done or how to do it. It is not merely that he, being bedridden, cannot go down to the drug store to get what is needed, but that he would, even if well, not be qualified to do what is needed and to judge what needs to be done."27

Thorax 2005;60:177-178.

doi: $10.1136 /$ thx.2004.033506

Correspondence to: Professor C J Griffiths, Institute of Community Health Sciences, Barts and the London, Queen Mary's School of Medicine and Dentistry, London E1 4NS; c.j.griffiths@qmul.ac.uk

\section{REFERENCES}

1 Gibson PG, Powell H, Coughlan J, et al. Selfmanagement education and regular practitione review for adults with asthma (Cochrane Review). The Cochrane Library. Issue 1. Oxford: Update Software, 2003:1-47.

2 Wanless D. Securing our future health: taking a long-term view. London: HM Treasury, 2002.

3 Donaldson L. Expert patients usher in a new era of opportunity for the NHS. BMJ 2003;326:1279-80.

4 Jones A, Pill R, Adams S. Qualitative study of views of health professionals and patients on guided self management plans for asthma. $B M$ 2000;321:1507-10.
5 Fitzpatrick M. The doctors they deserve. Br J Gen Pract 2004;54:795.

6 Scambler G. Health and social change. Buckingham: Oxford University Press, 2002.

7 Brown JB, Boles M, Mullooly JP, et al. Effect of clinician communication skills training on patient satisfaction. A randomized, controlled trial. Ann Intern Med 1999;131:822-9.

8 Barry CA, Stevenson FA, Britten N, et al. Giving voice to the lifeworld. More humane, more effective medical care? A qualitative study of doctor-patient communication in general practice. Soc Sci Med 2001;53:487-505.

9 Stevenson FA, Britten N, Barry CA et al. Selftreatment and its discussion in medical consultations: how is medical pluralism managed in practice? Soc Sci Med 2003;57:513-27.

10 Stevenson FA, Barry CA, Britten N, et al. Doctorpatient communication about drugs: the evidence for shared decision making. Soc Sci Med 2000;50:829-40.

11 Jones IR, Berney L, Kelly M, et al. Is patient involvement possible when decisions involve scarce resources? A qualitative study of decisionmaking in primary care. Soc Sci Med 2004;59:93-102.

12 Griffiths C, Kaur G, Gantley M, et al. Influences on hospital admission for asthma in south Asian and white adults: qualitative interview study. $B M J$ 2001;323:962.

13 Clark NM, Gong M, Schork MA, et al. Impact of education for physicians on patient outcomes. Pediatrics 1998;101:831-6.

14 Bandura A. Self-efficacy: toward a unifying theory of behavioral change. Psychol Rev 1977;84:191-215.

15 Lorig K, Sobel D, Stewart A. Evidence suggesting that a chronic disease self-management program can improve health status while reducing hospitalization: a randomized trial. Med Care 1999:37:5-14.

16 Lupton D. Consumerism, reflexivity and the medical encounter. Soc Sci Med 1997;45:373-81.

17 Lorig K. Partnerships between expert patients and physicians. Lancet 2002;359:814-5.

18 Stewart MA. Effective physician-patient communication and health outcomes: a review. CMAJ 1995; 152:1423-33

19 Guadagnoli E, Ward P. Patient participation in decision-making. Soc Sci Med 1998;47:329-39.

20 Lewin SA, Skea ZC, Entwistle V, et al. Interventions for providers to promote a patientcentred approach in clinical consultations (Cochrane Review). In: The Cochrane Library. Issue 1. Chichester: John Wiley \& Sons, 2004.

21 Caress A-L, Beaver K, Luker K, et al. Involvement in treatment decisions: what do adults with asthma want and what do they get? Results of a cross sectional survey. Thorax 2005;60:199-205.

22 Strull WM, Lo B, Charles G. Do patients want to participate in medical decision making? JAMA 1984;252:2990-4.

23 Adams RJ, Smith BJ, Ruffin RE. Patient preferences for autonomy in decision making in asthma management. Thorax 2001;56:126-32.

24 Gibson PG, Talbot PI, Toneguzzi RC. Selfmanagement, autonomy, and quality of life in asthma. Chest 1995; 107:1003-8.

25 McKinstry B. Do patients wish to be involved in decision making in the consultation? A cross sectional survey with video vignettes. BMJ 2000;321:867-71

26 Foster G, Griffiths C. Ethnic differences in consultations for asthma: a qualitative and quantitative study. Cambridge: Society for Academic Primary Care, Annual Scientific Meeting, 2003.

27 Parsons T. The social system. New York: Free Press, 1951. 
Exhaled biomarkers in asthma

\section{The exhaled biomarker puzzle: bacteria play their card in the exhaled nitric oxide-exhaled breath condensate nitrite game}

I Horvath

\section{Exhaled NO and nitrite as potential biomarkers in asthma}

$\checkmark \mathrm{k}$ he measurement of exhaled biomarkers has gained increasing interest in recent years, mainly driven by the unmet clinical need to monitor airway inflammation and the response to antiinflammatory treatment. The current issue of Thorax contains two important publications in this rapidly growing field. The study by Pijnenburg et al shows how exhaled nitric oxide (NO) measurement can serve clinical practice, ${ }^{1}$ while the investigation by Marteus et al draws attention to the potential pitfalls of measuring nitrite in exhaled breath condensate (EBC). ${ }^{2}$

It was hardly more than a decade between the discovery by Gustaffson et al in 1991 that the exhaled breath contains $\mathrm{NO}$ and the approval of such a measurement for clinical practice to monitor the effect of anti-inflammatory treatment in asthma. ${ }^{3}$ The road has been paved by approximately 2000 publications on the measurement of the fractional concentration of exhaled nitric oxide $\left(\mathrm{FE}_{\mathrm{NO}}\right)$ in health and disease, including three guidelines which provide methodological recommendations by internationally known experts in the field and endorsed by the European Respiratory Society (ERS) and/or the American Thoracic Society (ATS). ${ }^{5-7}$ By using these recommendations, exhaled NO can be measured reproducibly and data from different laboratories can be compared.

Exhaled NO has been extensively studied as a marker of airway inflammation in asthma and it serves as a prototype for the application of biomarkers to the management of the inflammatory component of asthma. Can monitoring $\mathrm{FE}_{\mathrm{NO}}$ in addition to symptoms and spirometry contribute to asthma control? The paper by Pijnenburg et al in this issue of Thorax provides a positive answer to this question. ${ }^{1}$ In a longitudinal study the authors determined whether $\mathrm{FE}_{\mathrm{NO}}$ predicted asthma relapse in 40 children with asymptomatic asthma followed for
24 weeks after discontinuation of treatment with inhaled corticosteroids (ICS). The children were enrolled in the study at the moment when discontinuation of ICS was considered because of lack of symptoms for more than 6 months at a stable dose of ICS. This ensured that the study was undertaken in a real clinical context (and the withdrawal of treatment did not occur solely for the purpose of the study). The main finding was that an increase in $\mathrm{FE}_{\mathrm{NO}}$ predicted loss of asthma control in patients with no symptoms or changes in spirometric parameters. The authors found that increased $\mathrm{FE}_{\mathrm{NO}}$ predicted asthma relapse with a sensitivity of $71 \%$ and a specificity of $93 \%$ using a cut-off $\mathrm{FE}_{\mathrm{NO}}$ value of $49 \mathrm{ppb}$. This finding has important clinical implications because an increase in $\mathrm{FE}_{\mathrm{NO}}$ warns the clinician of worsening airway inflammation, indicating the need to start treatment before symptoms appear. In another longitudinal study Jones et $a l^{8}$ studied $\mathrm{FE}_{\mathrm{NO}}$ as a predictor of loss of asthma control in relation to withdrawal of steroids in adults. Exhaled NO levels were measured weekly for 11 weeks in 78 subjects with asthma who abruptly stopped treatment with ICS. The authors found that, in subjects who eventually experienced loss of control, exhaled NO levels increased more rapidly and to significantly higher levels than in those remaining clinically stable. Similar to the results of Pijnenburg et al in children, they found that exhaled NO levels measured at the visit before loss of control occurred predicted the upcoming exacerbation (positive predictive value of $80-90 \%$ ) at a time when symptoms were stable.

Although as yet we do not know whether using exhaled NO measurements to guide anti-inflammatory treatment in asthma in addition to traditional means of monitoring would improve asthma control, both studies indicate that exhaled NO can serve as a marker of loss of asthma control and may be useful in clinical decision making.

While a decade was enough for exhaled NO measurement to enter clinical practice, the same decade was only good enough to give a boom to research for measurement of biomarkers in EBC. It is easy to collect, requiring only the noninvasive collection of exhaled breath for 10-20 minutes in a cold trap. The fluid obtained is a complex diluted solution of diverse biomarkers with various chemical stabilities including a number of constituents. ${ }^{9}{ }^{10}$ Because of the complexity of EBC and the fact that it is a much diluted sample, there are still a number of uncertainties surrounding it. Although there is an expectation that this sampling method will be clinically useful, there are still several unresolved issues, many of which are highlighted in the report by the ERS/ATS Task Force entitled "Exhaled Breath Condensate" which is awaiting ATS approval for publication.

In this issue of Thorax an important study by Marteus et $a l^{2}$ addresses the relation between exhaled NO and EBC nitrite/nitrate concentration. The authors performed a carefully designed study which assessed the source of nitrite in orally collected EBC, compared nitrite levels between oral and tracheal EBC samples, and investigated the influence of nitrate intake and antibacterial mouthwash on the nitrite concentration in oral EBC samples, nasal air condensates, and on $\mathrm{FE}_{\mathrm{NO}}$. Their findings can be summarised as follows: (1) nitrate levels in EBC are influenced by dietary intake; (2) nitrate is reduced to nitrite primarily by bacterial activity which takes place mainly in the oropharyngeal tract in healthy subjects; and (3) there is a substantial contribution of nitrite from the oropharyngeal tract during oral EBC collection. The findings of this study draw attention to the acknowledged pitfall of oral EBC sampling-namely, the potential nasooropharyngeal influence on mediator levels. They also question, to some extent, the reliability of oral EBC nitrite in reflecting lower airway NO production and its ability to serve as a marker of airway inflammation. ${ }^{11-15}$ The study also highlights the importance of potential external contamination (the authors covered the condensing surface with a specific plasma layer to minimise nitrite contamination) and emphasises the need for great care when measuring mediators which occur in such a low concentration in the EBC.

Thorax 2005:60:179-180. doi: 10.1136/thx.2004.034603

Correspondence to: Dr I Horvath, National Koranyi Institute for Pulmonology, Department of Pathophysiology, Budapest, Piheno u. 1, H-1529 Hungary; hildiko@koranyi.hu 


\section{REFERENCES}

1 Pijnenburg MW, Hofhuis W, Hop WC, et al. Exhaled nitric oxide predicts asthma relapse in children with clinical asthma remission. Thorax 2005;60:215-18

2 Marteus H, Törnberg DC, Weitzberg E, et al. Origin of nitrite and nitrate in nasal and exhaled breath condensate and the relation to nitric oxide formation. Thorax 2005;60:219-25.

3 Gustafsson LE, Leone AM, Persson MG et al. Endogenous nitric oxide is present in the exhaled air of rabbits, guinea pigs and humans. Biochem Biophys Res Commun 1991;181:852-7.

4 Silkoff $P$, Carlson M, Bourke T, et al. The Aerocrine exhaled nitric oxide monitoring system NIOXX is cleared by the US Food and Drug Administration for monitoring therapy in asthma. J Allergy Clin Immunol 2004;1 14:1242-56.

5 Kharitonov S, Alving K, Barnes PJ. Exhaled and nasal nitric oxide measurements: recommendations. European Respiratory Society Task Force. Eur Respir J 1997;10:1683-93.

6 American Thoracic Society. Recommendations for standardized procedures for the on-line and offline measurement of exhaled lower respiratory nitric oxide and nasal nitric oxide in adults and children-1999. Am J Respir Crit Care Med 1999;160:2104-17.

7 Baraldi E, de Jongste JC. Measurement of exhaled nitric oxide in children. Eur Respir J 2001;20:223-37.

8 Jones SL, Kittelson J, Cowan JO, et al. The predictive value of exhaled nitric oxide measurements in assessing changes in asthma control. Am J Respir Crit Care Med 2001; 164:738-43

9 Kharitonov SA, Barnes PJ. Exhaled markers of pulmonary disease. Am J Respir Crit Care Med 2001;163:1693-722.

10 Horvath I. Exhaled breath condensate in disease monitoring. Clin Pulm Med 2003;10:195-200.
11 Dweik RA, Comhair SAA, Gaston B, et al. Nitric oxide chemical events in the human airway during the immediate and late antigen induced asthmatic response. Proc Natl Acad Sci USA 2001:98:2622-7.

12 Hunt J, Byrns RE, Ignarro L, Gaston B. Condensed expirate nitrite as a home marker for acute asthma. Lancet 1995;346: 1235-6.

13 Ganas K, Loukides S, Papatheodorou G, et al. Total nitrite/nitrate in expired breath condensate of patients with asthma. Respir Med 2001;95:649-54.

14 Kharitonov SA, Donnelly LE, Montuschi P, et al. Dose-dependent onset and cessation of action of inhaled budesonide on exhaled nitric oxide and symptoms in mild asthma. Thorax 2002; 57:889-96.

15 Formanek W, Inci D, Lauener RP, et al. Elevated nitrite in breath condensates of children with respiratory disease. Eur Respir $J$ 2002;19:487-91.

\section{Brave new world for interventional bronchoscopy}

\section{T P Toma, D M Geddes, P L Shah}

\section{New applications for interventional bronchoscopy}

U ntil recently, interventional bronchoscopy was limited to foreign body removal, debulking endobronchial tumours, or insertion of stents for the palliation of lung cancer. Most of these procedures are performed with a rigid bronchoscope under general anaesthesia by thoracic surgeons. As a result, only a few respiratory physicians developed an interest in interventional bronchoscopy. The small range of interventions has meant that, up to now, interventional bronchoscopy has been less glamorous than, for example, interventional cardiology.

Will this situation change? Firstly, there is an increased interest in transbronchial fine needle aspiration (TBNA) for staging lung cancer and in endobronchial ultrasound guided TBNA. ${ }^{1}$ The latter technique samples suspicious lymph nodes as small as $5 \mathrm{~mm}$ and has the potential for replacing mediastinoscopy. Secondly, tumours can be debulked with electrocautery, photodynamic therapy or lasers, and stents can be inserted under local anaesthesia with flexible bronchoscopes.

Recent research has driven an expansion of interventional bronchoscopy for some of the more common non-malignant respiratory diseases. Bronchial thermoplasty for the treatment of asthma is close to receiving FDA approval. This procedure, performed under local anaesthesia, involves the obliteration of smooth muscle in airways larger than $3 \mathrm{~mm}$ by applying radiofrequency energy. An endobronchial probe is passed through the working channel of the bronchoscope and applied to the airway wall. A controlled amount of energy is delivered which heats and destroys the muscle. Smooth muscle ablation causes a reduction in bronchial hyperreactivity and early studies suggest an improvement in asthma control. Pilot human trials have shown that the method is safe and can decrease airway hyperreactivity in patients with moderate asthma. ${ }^{23}$ Studies on patients with more severe or steroid dependent asthma are currently underway.

A number of procedures are being developed to improve breathlessness in severe emphysema. These aim to achieve volume reduction by bronchoscopy rather than surgery. The basic idea is to induce collapse of the worst affected lobe or segments by blocking the relevant airways with one-way valves. A number of such valves are available and have been designed to block inspiration while allowing drainage of expired air and secretions. This results in controlled deflation of the target segment or lobe. The valves are inserted directly through the working channel of the fibrescope or over a guide wire using the Seldinger technique.
More than 100 patients have been treated in this way and the safety record to date is encouraging. ${ }^{4-6}$ The valves remain in place and have only seldom been implicated in cough or distal infection. Worthwhile improvements in lung function and quality of life have been reported in up to a third of patients and failure is probably due to collateral ventilation from surrounding lung units. This is not surprising since only patients with very severe emphysema have so far been treated and more work needs to be done to define the most suitable patients. A pivotal randomised trial is now underway.

While bronchoscopic valve placement has been proposed for patchy (heterogeneous) emphysema, an alternative intervention has been suggested for diffuse (homogeneous) emphysema. This involves the creation of extraanatomical airways to bypass the flow limiting segment airways in expiration. A needle catheter is used to make fenestrations connecting emphysematous lung to nearby cartilaginous airways, and these holes are held open by "spiracles" (similar to small vascular stents). Pilot studies have shown that these fenestrations can be created safely and have a beneficial effect on lung function..$^{8}$ There is, however, a tendency for the fenestrations to become blocked by granulation tissue.

Bronchoscopic instillation of delivery systems for slow release of drugs may open up new perspectives in the localised treatment of lung conditions. Some polymers have thermotropic properties and so behave as liquids at room temperature but form gels at body temperature. These can be injected into a part of the lung where they are cleared slowly and act as a drug efflux reservoir. These polymers also have a number of influences on cells ranging from effects on drug efflux channels to energy depletion in mitochondria. One such 
effect is to improve the sensitivity of drug resistant cells to chemotherapy. The natural development of this technology would be to directly instil specific drug eluting gels into the lung via a bronchoscope. For example, a polymer and chemotherapy drug combination could be injected into the target segment of the lung where it forms a gel and gradually elutes the chemotherapeutic drug and also improves the sensitivity of the cells to the treatment. The development of this technology is speculative at present but may have widespread applications in respiratory medicine-ranging from chemotherapy for lung cancer through to gene therapy for cystic fibrosis and regenerative treatments in emphysema. ${ }^{9}$

These interventions stimulate the future of interventional bronchoscopy. Some may fail to become a clinical reality, but this is likely to be a fertile area of research in years to come. It is clear that interventional bronchoscopy is evolving and will have an impact on a greater number of patients with respiratory diseases in the future.

The authors thank Dr Atul Mehta (Cleveland Clinic) for his review and comments.

Thorax 2005;60:180-181.

doi: $10.1136 /$ thx.2004.029983

\section{Authors' affiliations}

T P Toma, National Heart and Lung Institute, Dovehouse Street, London SW3 6JY, UK D M Geddes, Royal Brompton Hospital, Sydney Street, London SW3 6NP, UK P L Shah, Royal Brompton Hospital, Sydney Street, London SW3 6NP, UK and the Chelsea \& Westminster Hospital, London SW10 9NH, UK

Correspondence to: $\operatorname{Dr}$ P L Shah, Department of Respiratory Medicine, Royal Brompton Hospital, Sydney Street, London SW3 6NP, UK; pallav.shah@imperial.ac.uk

\section{REFERENCES}

1 Krasnik M, Vilmann P, Larsen SS, et al. Preliminary experience with a new method of endoscopic transbronchial real time ultrasound guided biopsy for diagnosis of mediastinal and hilar lesions. Thorax 2003;58:1083-6.

2 Cox G, Miller J, McWilliams A, et al. Bronchial thermoplasty: one-year update. Paper presented at American Thoracic Society, Orlando, 2004

3 Laviolette M, Thomson N, Niven R, et al. Asthma intervention research (AIR) trial: early safety assessment of bronchial thermoplasty. Paper presented at American Thoracic Society, Orlando, 2004.

4 Toma TP, Hopkinson NS, Hillier J, et al. Bronchoscopic volume reduction with valve implants in patients with severe emphysema. Lancet 2003:361:931-3.

5 Snell GI, Holsworth L, Borrill ZL, et al. The potential for bronchoscopic lung volume reduction using bronchial prostheses: a pilot study. Chest 2003;124:1073-80

6 Yim AP, Hwong TM, Lee TW, et al. Early results of endoscopic lung volume reduction for emphysema. J Thorac Cardiovasc Surg 2004: 127:1564-73.

7 Lausberg HF, Chino K, Patterson GA, et al. Bronchial fenestration improves expiratory flow in emphysematous human lungs. Ann Thorac Surg 2003;75:393-7.

8 Rendina EA, De Giacomo T, Venuta F, et al. Feasibility and safety of the airway bypass procedure for patients with emphysema. J Thorac Cardiovasc Surg 2003;125:1294-9.

9 Kabanov AV, Batrakova EV, Alakhov VY. Pluronic block copolymers as novel polymer therapeutics for drug and gene delivery. $J$ Control Release 2002:82:189-212

\section{Muscling into cystic fibrosis airways}

\section{A M Sutcliffe, A J Knox}

\section{Remodelling of the airway smooth muscle layer is not confined to patients with severe CF but occurs also in those with mild to moderate disease}

M ost patients with cystic fibrosis (CF) develop progressive airflow obstruction. A subgroup of these patients also have airway hyperresponsiveness to inhaled bronchoconstricting agents $^{12}$ and reversibility of airflow obstruction in response to bronchodilators. ${ }^{3}$ Parallels have been drawn between these observations and other airway diseases manifesting with airway obstruction and bronchial hyperresponsiveness such as asthma and chronic obstructive pulmonary disease (COPD). This led to speculation that remodelling of the airway smooth muscle (ASM) layer may contribute to bronchial hyperresponsiveness in CF.

Studies in the past have been restricted to patients with severe CF. Pathological studies of the lungs of these patients obtained either at necropsy or following transplantation or lobectomy showed an increase in smooth muscle area compared with healthy controls or patients with COPD. ${ }^{45}$ In this issue of Thorax Hays et $a l^{6}$ have, for the first time, studied the ASM layer in patients with mild to moderate CF using bronchoscopy and design based stereology. They found that the volume of smooth muscle in the airway submucosa in subjects with CF was higher than in normal controls and, furthermore, that this difference was attributable to smooth muscle cell hyperplasia rather than hypertrophy. This study raises several interesting questions. 1. Is this increase in the volume of the smooth muscle layer responsible for the airway hyperresponsiveness seen in many CF patients? 2. What factors are produced in the CF airway that could promote ASM hypertrophy? 3. Is there a relationship between the defective ion transport underlying CF pathophysiology and smooth muscle function in the CF airway?

Is the smooth muscle cell hyperplasia demonstrated by Hays et al sufficient to explain airway hyperresponsiveness in CF patients? Mathematical modelling approaches suggest that changes in airway dimensions in CF, including an increase in the smooth muscle area, probably contribute to airflow obstruction and bronchial hyperresponsiveness in these patients. ${ }^{4}$ Interestingly, tumour necrosis factor $\alpha(\mathrm{TNF}-\alpha)$, a cytokine found in increased amounts in the CF airway, has been shown to potentiate ASM contraction in response to cholinergic stimulation in vitro, ${ }^{7}$ and there is evidence that TNF- $\alpha$ induces a hypercontractile phenotype by enhancing agonist induced calcium signals, as well as agonist induced force generation. ${ }^{8}$ Thus, it may be that factors other than ASM hyperplasia alone contribute to bronchial hyperresponsiveness in CF. It would be interesting to investigate whether the presence and degree of airway hyperresponsiveness correlates with smooth muscle hyperplasia in these patients. The difficulty is that it is not possible to study the small airways-which collectively make the greater contribution to airflow obstruction-in the subgroup of patients with mild to moderate disease.

There are interesting similarities and contrasts between the inflammatory milieu found in the asthmatic and CF airways. Inflammation in $\mathrm{CF}$ is primarily neutrophil driven whereas, in asthma, T lymphocytes, eosinophils and mast cells are of greater importance although neutrophils may play a role in severe asthma. This has consequences for the range of cytokines and mediators that predominate in the inflamed airway. Airway inflammation and remodelling involves not just inflammatory cells but also structural cells such as fibroblasts, epithelial cells, and ASM cells. Inflammatory and structural cells 
produce cytokines, mediators, matrix modifying enzymes, chemokines, and growth factors that initiate and perpetuate inflammation and remodelling. The interplay between these cells and the multitude of biologically active molecules that they secrete is complex and not fully understood. However, those factors that promote proliferation of ASM cells in vitro include growth factors (such as basic fibroblast growth factor, ${ }^{\prime}$ transforming growth factor- $\beta,{ }^{9}$ platelet derived growth factor, ${ }^{10}$ epidermal growth factor $^{11}$ and insulin-like growth factor ${ }^{12}$ ), mediators including endothelin- $1^{13}$ and cysteinyl leukotrienes, ${ }^{12}{ }^{14}$ proteolytic enzymes such as thrombin ${ }^{15}$ and mast cell derived tryptase, ${ }^{16}$ and cytokines including interleukin (IL)-1 $\beta .{ }^{17}$ Many of these factors are found in increased amounts in the asthmatic airway and their influence on ASM function and airway remodelling has been the subject of intense study over the last decade. Some of these factors are also present in inflamed airways in CF.

It remains a matter of debate whether inflammation in the CF lung is driven by the opportunistic infections characteristic of this disease or whether it begins early in the disease, independent of lung infection. However, what is clear is that a chain of events occurs leading to a vicious cycle of infection, inflammation, lung tissue damage and further vulnerabililty to infection. Bacteria stimulate macrophages to produce IL-1 $\beta$ and TNF- $\alpha$ which, in turn, stimulate epithelial cells to produce chemokines such as IL-8, cytokines such as IL-1, and growth factors such as GM-CSF. IL-8 attracts neutrophils to the inflammatory site where they release $\mathrm{LTB}_{4}$, reactive oxygen species, and proteases such as elastase which damage airway structural proteins and further stimulate cytokine production by epithelial cells. Since ASM mitogenesis can be stimulated in vitro by the actions of proteolytic enzymes including thrombin ${ }^{15}$ and tryptase, ${ }^{16}$ it is interesting to speculate whether proteases in the CF airway may have a similar effect. Other mediators and cytokines found in increased amounts in the CF airway which could promote ASM proliferation include the cysteinyl leukotrienes which augment growth factor induced ASM proliferation, ${ }^{14}$ and the potent smooth muscle mitogen and bronchoconstrictor endothelin- $1 .{ }^{18}$

In $\mathrm{CF}$ a number of different mutations in the gene encoding the cystic fibrosis transmembrane conductance regulator (CFTR) lead to defective chloride secretion by epithelial cells and disordered ion transport. This alters the composition of the airway surface liquid, predisposing to pulmonary infection. In the intestine the myofibroblast layer contributes to chloride secretion by intestinal epithelial cells through the production of prostaglandin $\mathrm{E}_{2}\left(\mathrm{PGE}_{2}\right)$ mediated by cyclooxygenase in response to inflammatory cytokines ${ }^{19}$ and thrombin. ${ }^{20}$ It is possible that ASM derived factors in the $\mathrm{CF}$ airway can modify airway epithelial ion transport. Indeed, it is known that a number of inflammatory cytokines and mediators increase $\mathrm{PGE}_{2}$ production by ASM cells in vitro $^{21} 22$ and, furthermore, that $\mathrm{PGE}_{2}$ - the dominant prostanoid produced by ASM under inflammatory conditions-stimulates chloride secretion by airway epithelial cells. ${ }^{23}$ It may be that ASM hyperplasia in CF is an adaptive response which compensates, in part, for defective chloride secretion.

Is it possible that the defect in the CFTR itself contributes to ASM hyperplasia in CF? Interestingly, recently published data show that inhibition of the $\mathrm{Na}-\mathrm{K}-2 \mathrm{Cl}$ co-transporter by diuretics inhibits ASM proliferation in vitro, ${ }^{24}$ suggesting that alterations in ion flux may modify hypertrophic or hyperplastic processes in these cells.

The findings of Hays et al add an important contribution to our knowledge about airway remodelling in $\mathrm{CF}-$ specifically that changes in the ASM layer are not confined to patients with severe disease but are present in those with mild to moderate disease. This is of particular importance as it suggests a possible mechanism underlying the airway obstruction and hyperresponsiveness observed in these patients in the clinic. The biological mechanisms underlying ASM hyperplasia in CF warrant further study which will enhance our understanding of the pathophysiology of this disease and may lead to novel approaches to treatment.

Thorax 2005;60:181-182.

doi: $10.1136 /$ thx.2004.035840

\section{Authors' affiliations}

A M Sutcliffe, A J Knox, Division of Respiratory Medicine, University of Nottingham, Nottingham, UK

Correspondence to: Professor A J Knox, Division of Respiratory Medicine, Nottingham City Hospital, Hucknall Road, Nottingham NG5 1PB, UK; alan.knox@nottingham.ac.uk

\section{REFERENCES}

1 Weinberger $M$. Airways reactivity in patients with CF. Clin Rev Allergy Immunol 2002;23:77-85.

2 Mitchell I, Corey M, Woenne R, et al. Bronchial hyperreactivity in cystic fibrosis and asthma. J Pediatr 1978;93:744-8

3 van Haren EH, Lammers JW, Festen J, et al. Bronchodilator response in adult patients with cystic fibrosis: effects on large and small airways. Eur Respir J 1991;4:301-7.

4 Tiddens HA, Koopman LP, Lambert RK, et al. Cartilaginous airway wall dimensions and airway resistance in cystic fibrosis lungs. Eur Respir $\mathrm{J}$ 2000; 15:735-42.

5 Tomashefski JF Jr, Bruce M, Goldberg HI, et al. Regional distribution of macroscopic lung disease in cystic fibrosis. Am Rev Respir Dis 1986;133:535-40.

6 Hays SR, Ferrando RE, Carter R, et al. Structural changes to airway smooth muscle in cystic fibrosis. Thorax 2005:60:226-8.

7 Sukkar MB, Hughes JM, Armour CL, et al. Tumour necrosis factor-alpha potentiates contraction of human bronchus in vitro. Respirology 2001;6:199-203.

8 Amrani $Y$, Chen H, Panettieri RA Jr. Activation of tumor necrosis factor receptor 1 in airway smooth muscle: a potential pathway that modulates bronchial hyper-responsiveness in asthma? Respir Res 2000;1:49-53.

9 Ediger TL, Toews ML. Synergistic stimulation of airway smooth muscle cell mitogenesis. J Pharmacol Exp Ther 2000;294:1076-82.

10 Simon AR, Takahashi S, Severgnini M, et al. Role of the JAK-STAT pathway in PDGF-stimulated proliferation of human airway smooth muscle cells. Am J Physiol Lung Cell Mol Physiol 2002;282:L1296-304.

11 Ediger TL, Danforth BL, Toews ML. Lysophosphatidic acid upregulates the epidermal growth factor receptor in human airway smooth muscle cells. Am J Physiol Lung Cell Mol Physiol 2002;282:L91-8

12 Cohen P, Noveral JP, Bhala A, et al. Leukotriene D4 facilitates airway smooth muscle cell proliferation via modulation of the IGF axis. Am J Physiol 1995;269:L151-7.

13 Stewart AG, Grigoriadis G, Harris T. Mitogenic actions of endothelin-1 and epidermal growth factor in cultured airway smooth muscle. Clin Exp factor in cultured airway smooth musc
Pharmacol Physiol 1994;21:277-85.

14 Holgate ST, Peters-Golden M, Panettieri RA, et al. Roles of cysteinyl leukotrienes in airway inflammation, smooth muscle function, and remodeling. J Allergy Clin Immunol 2003;111(1 Suppl):S18-34; discussion S34-6.

15 Tran T, Stewart AG. Protease-activated receptor (PAR)-independent growth and pro-inflammatory actions of thrombin on human cultured airway smooth muscle. Br J Pharmacol 2003; 138:865-75

16 Brown JK, Jones CA, Rooney LA, et al. Tryptase's potent mitogenic effects in human airway smooth muscle cells are via nonproteolytic actions. Am J Physiol Lung Cell Mol Physiol 2002;282:L197-206.

17 De S, Zelazny ET, Souhrada JF, et al. Interleukin-1 beta stimulates the proliferation of cultured airway smooth muscle cells via platelet-derived growth factor. Am J Respir Cell Mol Biol 1993;9:645-51.

18 Chalmers GW, Macleod KJ, Sriram S, et al. Sputum endothelin-1 is increased in cystic fibrosis and chronic obstructive pulmonary disease. Eur Respir J 1999;13:1288-92.

19 Hinterleitner TA, Saada Jl, Berschneider HM, et al. IL-1 stimulates intestinal myofibroblast COX gene expression and augments activation of $\mathrm{Cl}^{-}$ secretion in T84 cells. Am J Physiol 1996;271:C1262-8

20 Seymour ML, Zaidi NF, Hollenberg MD, et al. PAR 1-dependent and independent increases in COX-2 and PGE2 in human colonic myofibroblasts stimulated by thrombin Am J Physiol Cell Physiol 2003;284:C1 185-92.

21 Pang LH, Knox AJ. Effect of interleukin-1 beta, tumour necrosis factor alpha and interferon gamma on the induction of cyclo-oxygenase 2 in cultured human airway smooth muscle cells. Br J Pharmacol 1997; 121:579-87.

22 Pang LH, Knox AJ. PGE 2 release by bradykinin in human airway smooth muscle cells: involvement of cyclooxygenase-2 induction. Am J Physiol 1997;273:L1 132-40.

23 Clayton AA, Holland E, Pang $\mathrm{LH}$, et al. Interleukin-1 beta alters chloride efflux from calu-3 bronchial epithelial cells in an agonist specific manner. Am J Respir Crit Care Med 2004; 169:A670.

24 Iwamoto LM, Fujiwara N, Nakamura KT, et al. $\mathrm{Na}-\mathrm{K}-2 \mathrm{Cl}$ cotransporter inhibition impairs human lung cellular proliferation. Am J Physiol Lung Cell Mol Physiol 2004;287:L510-4. 